\title{
LEARNING THROUGH SIMULATION
}

\author{
Anna Abelsson \\ Department of Health Sciences, Karlstad University, Sweden
}

\begin{abstract}
With simulation, caregivers are given the opportunity to improve their knowledge and skills. With simulation, both theoretical and practical knowledge is taught. With the experiences that simulation creates, critical thinking and better care are developed. Learning through simulation complements the learning that takes place in everyday work and can have a positive effect of the advances of the care profession. The purpose of simulation may vary and different learning theories are used, both based on learning objectives and the purpose of the simulation. The experience gained from simulation prepares caregivers on how similar complex situations can be handled in the future.
\end{abstract}

KEY WORDS: simulation, experiential learning theory, theoretical knowledge, practical skills

Disaster Emerg Med J 2017; 2(3): 125-128

\section{INTRODUCTION}

Caregivers' knowledge, skills and experience are of great importance for ensuring good quality and safe health care in all contexts of care. To improve health care safety, caregivers need education and training before they are made responsible for the patient. This is one of the reasons that simulation is becoming more popular in health care. With simulation, caregivers improve their knowledge and skills and gain an enhanced confidence in the care of injured and sick patients. The following text describes simulation as a learning process in which knowledge, skills and experience are integrated.

\section{THE LEARNING PROCESS IN SIMULATION}

According to Dewey [1], the learning process is an improvement of knowledge through continuous training. "Learning by doing" links knowledge, skills, and experience together. According to Dewey [1] and Kolb [2], reflection is an essential part of a learning process. Kolb's learning process theory, namely Experiential Learning Theory [2] which is based on Dewey's theory, assumes that the learner must be actively be involved in the experience of learning. The experiential learning theory is suitable for simulation because caregivers participate in realistic, dynamic and complex care situations [3]. To be active in learning means that as a participant, and an observer, one should reflect on what is happening during and after an activity $[2,4]$. When caregivers have a reflective approach based on either a theory or one's own, real or simulated experience, it results in improved critical thinking and, therefore, better care [5]. Based on Kolb's theory, the learner may move in a circle of knowledge, namely go from the concrete experience of observation and reflection to a more abstract conceptualization and, finally, into care action. Caregivers can, in this way, learn through problem solving and care action. The individual learning process can take place in an instant, or take days or weeks, depending on what is to be processed and how comprehensive the process is [2].

When learning by simulation is described as an active process, caregivers reflect using theory and experience [2]. Reflection on theoretical knowledge and practical experience is tied together. A concrete experience is understood in a new way in relation to theory, and the theory must, therefore, be understood in a new way in relation to a concrete experience. The choices of care actions performed 
by the caregiver change based on new knowledge and experience. The learning never stops and advances forward at all the time. Caregivers may apply their new knowledge and experience in the form of care actions. There is an increased understanding and preparedness for what might happen with the patient and the care actions to be taken and their possible consequences.

\section{LEARNING THEORETICAL KNOWLEDGE WITH SIMULATION}

A theoretical approach to learning includes remembering facts, concepts, and principles. Theoretical knowledge is learned, among other things, through instruction and can be evaluated with written tests [6]. To learn a theoretical topic, therefore, does not require any life experience $[7,8]$. It is a learning experience which consists of isolated knowledge about a disease or an injury in the form of physical signs and is understood by studying the patient's body [9]. With the help of simulation, this form of knowledge can be learned [6]. To reflect as by one self, or to reflect together with others, also develops one's theoretical knowledge [10]. The ability to reflect during the simulation may, therefore, result in better care $[11,12]$.

\section{LEARNING SKILLS WITH SIMULATION}

The practical skills learned in the simulation are applied and integrated with prior skills [13]. This form of skills cannot only be taught in the theory classroom; it needs, according to Benner and Tanner [4], to be learned in the care of patients. In healthcare, skills are defined by complex and skilfully executed care actions $[4,9]$. With simulation, scenarios and events can be staged based on the existing skills of the caregivers $[11,12]$. The inexperienced caregiver needs to learn basic skills, while the experienced caregiver can modify, improve and solidify their more advanced skills [10]. Both simulation of scenario or tests on single actions can help caregivers practice and improve their skills [14].

\section{GAINING EXPERIENCE WITH SIMULATION}

Caregivers' experience is based on an understanding of how a disease or injury can be experienced by the patient, in combination with having medical knowledge of the injury or illness [4]. To gain experience means to broaden one's ability to be responsive and reflect ethically. Caregivers' experience is grounded in social interaction with others and includes the development of ethical values and attitudes [7] which are in line with their own profession. Wisdom is incorporated and is fundamental to the caregiver's actions $[6,15]$. Wisdom can be acquired based on good role models and living through rewarding experiences. It is not something that is taught in lectures [8]. Caregivers' knowledge and experience merge together in meeting with patients.

A caregiver's inner library, which consists of experience, helps them to understand patients with more nuance and to choose the best care actions in various situations [16]. Thought, feeling, and action is integrated into the caregiver and are put into care actions with the patient's best interests in mind [17]. This is particularly important in emergency situations, as in prehospital emergency care, where quick and accurate assessments must be made and serve as the basis for several simultaneous care actions [18]. With the help of simulation, caregivers can train in meeting patients and other people at the site of an accident. Caregivers should strive to create and experience an authentic meeting with the patients, an aspect which Holmberg and Fagerberg [19], and Elmqvist et al. [15] point out as important. Simulation of patient scenarios, such as events concerning ethical problems, can advance caregivers in their profession. In simulation, effective learning is transformed into care action while the caregiver gains experience from managing different situations [6]. This simulation can, according to Rall and Dieckmann [20], be designed for training regarding what may be included in the future responsibilities of caregivers.

\section{VARIOUS LEARNING THEORIES FOCUS ON DIFFERENT PARTS OF THE SIMULATION}

The Cognitive Load Theory designs a simulation based on the caregiver's expected level of knowledge and experience, which includes minimizing disruptive or irrelevant outside influences. The simulation relies on the human being's ability to learn [21]. Kelly and Hager [22] focus their Informal Learning Theory on how the natural course of events during the simulation creates theoretical, practical and emotional learning for nurses. With a focus on the patient's inner world and outer behaviour, Smith et al. [23] compare simulation with the theatre. The patient, who in the simulation is represented by an 
actor, is trained in portraying patients in different care situations [23]. Husebo et al. [24] have a specific focus on the debriefing phase in simulated learning in their theory.

\section{CONCLUSION}

Learning through simulation complements the learning that takes place in everyday work and can enhance both the caregiver and the care given [25]. With simulation, skills that are rarely used, and therefore at risk of being forgotten, are exercised and retained [26]. When simulating acute care situations, caregivers are challenged to critically analyze problems and make decisions in a complex and rapidly changing health care environment, based on the information that is often limited or contradictory. Caregivers are given the opportunity to improve based on their own skill levels [27] and can build on existing knowledge [16, 28.29]. Experiences from simulations will prepare them for how similar complex situations can be handled in the future [30].

Funding sources: None declared. Conflict of interest: None declared.

\section{REFERENCES}

1. Dewey J. Experience and education. Touchstone, New York 1997.

2. Kolb D. Experiential learning: experience as the source of learning and development. Prentice, Englewood Cliffs 1984.

3. McCaughey CS, Traynor MK. The role of simulation in nurse education. Nurse Educ Today. 2010; 30(8): 827-832, doi: 10.1016/j. nedt.2010.03.005, indexed in Pubmed: 20483188.

4. Benner $P$, Tanner $C$. Clinical judgment: how expert nurses use intuition. Am J Nurs. 1987; 87(1): 23-31, indexed in Pubmed: 3642979.

5. Sanford PG. Simulation in nursing education: a review of the research. The Qualitative Report. 2010; 15(4): 1006-1011.

6. Kardong-Edgren S, Adamson K, Fitzgerald C. A Review of Currently Published Evaluation Instruments for Human Patient Simulation. Clinical Simulation in Nursing. 2010; 6(1): e25-e35, doi: 10.1016/j. ecns.2009.08.004.

7. Aristoteles. Den nikomachiska etiken. Daidalos. Göteborg 2012.

8. Saugstad T. Educational Theory and Practice in an Aristotelian Perspective. Scandinavian Journal of Educational Research. 2002; 46(4): 373-390, doi: 10.1080/0031383022000024561.

9. Nightingale F. Notes on nursung. What it is and what it is not. Appleton and company, New York 1989.

10. Poikela E, Poikela P. Towards simulation pedagogy: developing nursing simulation in a European network. Bibliothek in Rovaniemi, Rovaniemi 2012.
11. Alinier $G$, Hunt B, Gordon R, et al. Effectiveness of intermediate-fidelity simulation training technology in undergraduate nursing education. J Adv Nurs. 2006; 54(3): 359-369, doi: 10.1111/j.13652648.2006.03810.x, indexed in Pubmed: 16629920.

12. Scalese RJ, Obeso VT, Issenberg SB. Simulation technology for skills training and competency assessment in medical education. J Gen Intern Med. 2008; 23 Suppl 1: 46-49, doi: 10.1007/s11606-0070283-4, indexed in Pubmed: 18095044.

13. Garvey P, Liddil J, Eley $S$, et al. Trauma Tactics: Rethinking Trauma Education for Professional Nurses. J Trauma Nurs. 2016; 23(4): 210-214, doi: 10.1097/JTN.0000000000000218, indexed in Pubmed: 27414143.

14. Felton A, Holliday L, Ritchie $D$, et al. Simulation: a shared learning experience for child and mental health pre-registration nursing students. Nurse Educ Pract. 2013; 13(6): 536-540, doi: 10.1016/j. nepr.2013.04.003, indexed in Pubmed: 23660414.

15. Elmqvist $C$, Brunt $D$, Fridlund $B$, et al. Being first on the scene of an accident--experiences of ,doing' prehospital emergency care. Scand J Caring Sci. 2010; 24(2): 266-273, doi: 10.1111/j.14716712.2009.00716.x, indexed in Pubmed: 19732398.

16. Educating nurses: a call for radical transformation. Choice Reviews Online. 2010; 47(11): 47-6282-47-6282, doi: 10.5860/choice.47-6282.

17. Wiklund Gustin L, Bergbom I. Vårdvetenskapliga begrepp i teori och praktik. Nordic Journal of Vocational Education and Training. Studentlitteratur, Lund 2012.

18. Edmond $C B$. A new paradigm for practice education. Nurse Educ Today. 2001; 21(4): 251-259, doi: 10.1054/nedt.2000.0543, indexed in Pubmed: 11339867.

19. Holmberg M, Fagerberg I. The encounter with the unknown: Nurses lived experiences of their responsibility for the care of the patient in the Swedish ambulance service. Int J Qual Stud Health Well-being. 2010; 5, doi: 10.3402/qhw.v5i2.5098, indexed in Pubmed: 20640018.

20. Rall M, Dieckmann P. Safety culture and crisis resource management in airway management: general principles to enhance patient safety in critical airway situations. Best Pract Res Clin Anaesthesiol. 2005; 19(4): 539-557, indexed in Pubmed: 16408533.

21. Reedy G. Using Cognitive Load Theory to Inform Simulation Design and Practice. Clinical Simulation in Nursing. 2015; 11(8): 355-360, doi: 10.1016/j.ecns.2015.05.004.

22. Kelly $M$, Hager $P$. Informal Learning: Relevance and Application to Health Care Simulation. Clinical Simulation in Nursing. 2015; 11(8): 376-382, doi: 10.1016/j.ecns.2015.05.006.

23. Smith C, Gephardt E, Nestel D. Applying the Theory of Stanislavski to Simulation: Stepping into Role. Clinical Simulation in Nursing. 2015; 11(8): 361-367, doi: 10.1016/j.ecns.2015.04.001.

24. Husebø S, O'Regan $S$, Nestel D. Reflective Practice and Its Role in Simulation. Clinical Simulation in Nursing. 2015; 11(8): 368-375, doi: 10.1016/j.ecns.2015.04.005.

25. Maran NJ, Glavin RJ. Low- to high-fidelity simulation - a continuum of medical education? Med Educ. 2003; 37 Suppl 1: 22-28, indexed in Pubmed: 14641635. 
26. Gonzalez L, Kardong-Edgren S. Deliberate Practice for Mastery Learning in Nursing. Clinical Simulation in Nursing. 2017; 13(1): 10-14, doi: 10.1016/j.ecns.2016.10.005.

27. West C, Usher K, Delaney U. Unfolding case studies in pre-registration nursing education: lessons learned. Nurse Educ Today. 2012; 32(5): 576-580, doi: 10.1016/j.nedt.2011.07.002, indexed in Pubmed: 21824693.

28. Kim J, Park JH, Shin S, et al. Effectiveness of patient simulation in nursing education: meta-analysis. Nurse Educ Today. 2015; 35(1):
176-182, doi: 10.1016/j.nedt.2014.09.009, indexed in Pubmed: 25459172.

29. Yeun EJa, Bang HoY, Ryoo ENa, et al. Attitudes toward simulation-based learning in nursing students: an application of $Q$ methodology. Nurse Educ Today. 2014; 34(7): 1062-1068, doi: 10.1016/j. nedt.2014.02.008, indexed in Pubmed: 24629271.

30. Murphy S, Hartigan I, Walshe N, et al. Merging Problem-Based Learning and Simulation as an Innovative Pedagogy in Nurse Education Clinical Simulation in Nursing. 2011; 7(4): e141-e148, doi: 10.1016/j. ecns.2010.01.003. 